\title{
PEMBELAJARAN BAHASA INGGRIS MENGGUNAKAN MEDIA BATANG ES KRIM
}

\author{
Herlinda Dian Permana Ningsih \\ Email: denskb@gmail.com \\ UPTD SKB Kota Palembang
}

\begin{abstract}
Abstrak: Pengajaran Bahasa Inggris merupakan salah satu mata pelajaran yang dianggap menakutkan bagi warga belajar Paket B. Dalam artikel ini penulis mencoba memberikan suatu alternatif pengajaran Bahasa Inggris menyenangkan dan cukup efektif dengan menggunakan batang es krim sebagai media pembelajaran. Media pembelajaran ini diterapkan kepada warga belajar paket B binaan UPTD Sanggar Kegiatan Belajar (SKB) pada bulan Mei 2010. Penerapan pertama dengan 13 orang warga belajar dan penerapan kedua dengan 17 orang warga belajar. Penerapan metode pengajaran ini terhadap warga belajar paket $B$ terbukti dapat meningkatkan pemahaman warga belajar terhadap bacaan (reading comprehension), selain itu juga dapat meningkatkan motivasi belajar mereka terhadap mata pelajaran Bahasa Inggris.
\end{abstract}

Kata kunci: media batang es krim, bahasa Inggris, warga belajar

\section{TEACHING ENGLISH WITH ICECREAM STICKS AS A MEDIUM}

\begin{abstract}
Learning English often becomes dull ang frightening for participants of Package B. This articels presents an alternative teaching methode using icecream sticks as instructional media which have proved successful to create a jouyful learning. This method was practiced in teaching the participants of Package $B$ in UPTD SKB in May 2010 including 13 participants in the first application. The result shows that those method can significantly improve the reading comprehension and learning motivation of the participants to study English.
\end{abstract}

Keywords: icecream stick, English, learning participants.

\section{PENDAHULUAN}

Suksesnya program-program Pendidikan Non Formal di lembaga-lembaga dan Unit Pelaksana Teknis Dinas Pendidikan, seperti Sanggar Kegiatan Belajar (SKB) sangatlah bergantung kepada kualitas dan kinerja para pamong belajarnya. Pamong belajar yang merupakan salah satu pendidik di lingkungan Pendidikan Non Formal adalah tenaga profesional yang bertugas merencanakan dan melaksanakan proses pembelajaran, menilai hasil pembelajaran, melakukan pembimbingan dan pelatihan serta melakukan penelitian dan pengabdian kepada masyarakat terutama bagi tenaga yang berkualifikasi sebagai pamong belajar serta berpartisipasi dalam menyelenggarakan pendidikan (UU. No.20 Tahun 2003)

Sebagai ujung tombak program-program Pendidikan Non Formal, pamong belajar berhadapan langsung dengan target atau sasaran Pendidikan Non Formal yaitu masyarakat atau lebih tepatnya masyarakat menengah ke bawah. Dalam Kepmenkowasbangpan No. 25/KEP/MK.WASPAN/G/6/1999; pasal 1 ayat
1 disebutkan bahwa;

Pamong Belajar adalah Pegawai Negeri Sipil yang diberi tugas; tanggung jawab, wewenang dan hak secara penuh oleh pejabat yang berwenang untuk melaksanakan kegiatan belajar mengajar (KBM) dalam rangka pengembangan model dan membuat percontohan serta penilaian dalam rangka pengendalian mutu dan dampak pelaksanaan Program Pendidikan Luar Sekolah dan Pemuda serta Olah raga (Diklusepora).

Jadi jelas di sini bahwa salah satu tugas yang diemban oleh seorang pamong belajar adalah melaksanakan Kegiatan Belajar Mengajar (KBM). Itulah sebabnya mengapa pamong belajar sangat memegang peranan penting dalam program kesetaraan yaitu program Paket A setara SD, Paket B setara SMP dan Paket $C$ setara SMA. Dalam artikel ini, penulis menekankan pada fungsi pamong belajar dalam kualitasnya sebagai tutor paket, khususnya Paket $B$ setara SMP dan paket $C$ setara SMA karena mata pelajaran Bahasa Inggris menjadi salah satu mata ajar wajib. 
Menurut penulis mulai saat ini, dalam rekruitmen, seleksi dan pengangkatan pamong belajar, sudah waktunya pemerintah sebaiknya mempertimbangkan latar belakang pendidikan khususnya pendidikan bidang studi seperti matematika, Bahasa Inggris, ekonomi dan lain-lain. Hal ini terkait dengan peran pamong belajar sebagai pengajar atau tutor program paket $B$ setara SMP dan program paket C setara SMA. Tanpa latar belakang pendidikan bidang studi tertentu, pamong belajar akan sulit untuk menjadi tutor pada program kesetaraan sehingga jalan untuk dapat menggali potensi dan kreativitas menjadi lebih sempit. Ada juga pamong belajar yang mengabdikan diri pada program kesetaraan sebagai pendidik/tutor dan mereka adalah mantan kepala SD mutasi ke SKB. Hal ini sangat berpengaruh pada motivasi mereka untuk berkreativitas meningkatkan kompetensi dalam mengajar. Bagi pamong belajar yang kebanyakan berlatarbelakang pendidikan program studi Pendidikan Luar Sekolah (PLS), mereka tidak memiliki kemampuan mengajar pada suatu bidang studi tertentu untuk berperan aktif pada program kesetaraan baik paket $A$ setara SD, Paket B setara SMP maupun Paket C setara SMA.

Menurut Pardiyono (2010), mengajar adalah sebuah seni (art) yang memerlukan gaya dan teknik tertentu sehingga proses pembelajaran menjadi lebih menarik dan materi belajar menjadi lebih mudah diterima oleh para siswa. Oleh karena itu, agar penyampaiannya menjadi efektif, para guru dan calon guru perlu menerapkan gaya dan teknik tertentu sehingga proses pembelajaran menjadi lebih menarik, materi belajar menjadi lebih mudah diterima dan dikuasai oleh para siswa.

Penggunaan ice cream sticks dalam pembelajaran Bahasa Inggris ini terjadi ketika pada suatu hari , saat menunggu pelajaran akan dimulai, penulis melihat para warga belajar perempuan dan laki-laki masingmasing membawa "ice-cream sticks" atau batang es krim ini untuk digunakan sebagai suatu permainan. Pada setiap batang es krim tersebut tertulis nama, bisa satu atau dua nama. Nama yang tertera di situ adalah nama-nama tokoh di salah satu program acara suatu stasiun Televisi swasta, yaitu Cerita Upin \& Ipin dan kawan-kawan. Film animasi ini berasal dari negara Malaysia. Cerita Upin dan Ipin saat ini sangat digemari di Palembang dan segala sesuatu yang berbau cerita itu menjadi sangat digandrungi oleh anak-anak, tak terkecuali anak-anak warga belajar Paket B. Permainan yang mereka mainkan pun meniru permainan yang dilakukan upin, ipin dan teman-temannya di TV. Mereka dengan antusias memberitahu cara memainkan permainan tersebut, yaitu dengan cara meniup batang es krim itu, atau dengan cara menepuk lantai di belakang batang es krim tersebut secara bergantian agar batang es krim itu dapat menimpa batang es krim lawan, dan itu berarti menang.

Pada program kesetaraan, khususnya paket B setara SMP dan Paket C setara SMA, ada beberapa mata pelajaran yang dianggap sulit oleh peserta didik. Salah satunya adalah mata pelajaran Bahasa Inggris. Hal ini disebabkan, pertama, karena tingkat kesulitan mata pelajaran itu sendiri, kedua, karena kurang tepatnya metode/alat peraga yang digunakan pada mata pelajaran ini. Ketiga, karena kurangnya tingkat kecerdasan/motivasi peserta didik. Dari sinilah masalahnya berawal. Menurut Djoko Smd - Sapto Cahyono (2007), Bahasa Inggris merupakan bahasa yang sangat penting di era globalisasi yang ditandai dengan pesatnya perkembangan sains dan teknologi. Bahasa Inggris menjadi sangat vital untuk dikuasai, karena peranannya sebagai bahasa dari kedua hal tersebut.

Meskipun waktu belajar pada Jalur Pendidikan nonformal tidak setiap hari melainkan tiga kali seminggu namun bukan berarti kita harus menutup mata dan membiarkan para warga belajar kita tenggelam dalam ketidaktahuan dan ke'engganan' untuk mempelajari mata pelajaran ini. Jelas di sini tutor Bahasa Inggris paket B harus berperan aktif dalam usaha untuk membuat mata pelajaran ini menjadi lebih disenangi sehingga para warga belajar bersemangat untuk mempelajari Bahasa Internasional ini dengan tujuan mendapatkan hasil yang maksimal. Terlebih lagi jika tutor tersebut adalah seorang Pegawai Negeri Sipil (PNS) atau seorang pamong belajar.

Sebagai seorang Pegawai Negeri Sipil, seorang pamong belajar mempunyai tugas dan tanggung jawab yang besar terhadap kesuksesan para peserta didik dalam mengikuti program kesetaraan. Bagaimanapun caranya, salah satunya dengan cara memberikan media pembelajaran yang sesuai untuk para warga belajar agar dapat meningkatkan motivasi dan semangat belajar mereka terhadap pelajaran ini.

Sudah kita ketahui bersama, bahwa peserta didik atau warga belajar program pendidikan non formal tidak dapat kita samakan dengan siswa pada jalur pendidikan formal. Baik dari segi tingkat kecerdasan, tingkat ketekunan termasuk juga tingkat sosial ekonominya. Sebagai seorang pamong belajar/tutor, kita tidak bisa terlalu banyak berharap pada warga belajar. Pada jalur Pendidikan Nonformal (PNF) warga belajarnya rata-rata (meskipun tidak semua) serba minim; baik dari motivasi belajar, kecerdasan, ketekunan termasuk, yang paling banyak, minim ekonomi. Untuk itu seorang pamong belajar yang juga seorang tutor 
harus berperan aktif dan sabar dalam menghadapi warga belajar serta harus pandai-pandai 'menjaga hati' mereka agar tetap bersemangat mengikuti program kesetaraan sampai selesai. Terutama untuk mata pelajaran yang dianggap sulit bagi mereka. Misalnya; Bahasa Inggris. Apabila seorang pamong belajar yang juga sebagai tutor tidak memiliki motivasi dan kreativitas yang tinggi untuk membuat Bahasa Inggris menjadi mata pelajaran yang menyenangkan sehingga lebih diminati para peserta didik. Apabila mereka sudah tidak 'takut' lagi terhadap mata pelajaran ini, diharapkan motivasi mereka untuk belajar akan lebih tinggi sehingga pemahaman mereka terhadap Bahasa Inggris menjadi lebih baik. Untuk itulah, sebagai pamong belajar, penulis mencoba untuk memberikan suatu metode pembelajaran Bahasa Inggris dengan menggunakan Ice Cream Sticks atau batang es krim pada program kesetaraan Paket B setara SMP.

Penulisan artikel tentang pengajaran menggunakan media batang es krim ini bertujuan agar (1) proses atau Kegiatan Belajar Mengajar (KBM) Bahasa Inggris menjadi menarik dan menyenangkan bagi para warga belajar sehingga diharapkan motivasi belajar mereka pada pelajaran Bahasa Inggris akan lebih tinggi, (2) para peserta didik paket $B$ setara dapat lebih mudah menganalisis kalimat Bahasa Inggris dengan kalimat Bahasa Indonesia, (3) para peserta didik paket $B$ setara SMP dapat terbiasa menyusun kalimat - kalimat Bahasa Inggris menjadi satu passage atau bacaan, dan (4) para peserta didik/warga belajar paket $\mathrm{B}$ mendapat pemahaman yang lebih mendalam terhadap passage atau bacaan sehingga dapat menjawab pertanyaan pemahaman (comprehension questions) yang diberikan

Pembelajaran dengan menggunakan media batang es krim ini diharapkan dapat memberi manfaat kepada (1)Tutor Bahasa Inggris, baik yang bertugas sebagai tutor saja maupun bagi pamong belajar yang juga berprofesi sebagai tutor Bahasa Inggris sehingga dapat membantu dalam memberi pelajaran kepada para peserta didik; (2) Sanggar Kegiatan Belajar (SKB), agar metode pembelajaran Bahasa Inggris dapat menjadi suatu motivasi untuk dapat dikembangkan sehingga metode batang es krim ini dapat menjadi metode untuk dapat digunakan pada mata pelajaran lain; (3)Pendidikan NonFormal, agar metode pembelajaran menggunakan ice-cream sticks ini dapat memberikan kontribusi yang positif bagi dunia Pendidikan Non-Formal (PNF)

\section{Penerapan Media Batang Es Krim}

Penerapan karya nyata ini dilakukan dalam 2 (dua) tahap atau 'two-shots system"', yaitu tahap/pem- belajaran pertama tanpa menggunakan media pembelajaran ice-cream sticks dan tahap/pembelajaran kedua dengan menggunakan media batang es krim ini. Penulis melakukan hal ini karena penulis berasumsi adanya perbedaan yang cukup signifikan terhadap keberhasilan para peserta didik dalam memahami bacaan yang diberikan. Dengan penerapan ini, penulis yakin, warga belajar akan dapat meningkatkan tingkat pemahaman mereka terhadap isi bacaan.

Hasil ini akan dianalisis secara sederhana dengan menggunakan metode kriteria (criterion-reference method). Pembelajaran menggunakan batang es krim ini diterapkan pada warga belajar kelas VIII paket B setara SMP berjumlah 13 warga belajar (dinamai dengan WB-1 s/d WB-13) pada pembelajaran pertama dan 17 warga belajar (tambahan 4 WB dinamai dengan WB-14 s/d-17) pada pembelajaran kedua, di Kelurahan Kemang Agung Kertapati Palembang, binaan UPTD SKB Kota Palembang. Sebelumnya warga belajar ini sudah diberi materi 'simple present tense'

Berikut ini adalah bacaan atau materi pembelajaran pertama yang diajarkan tanpa menggunakan ice cream sticks atau batang es krim

\section{Koko is Sick}

There is a car in front of Koko's house.

It is a doctor's car.

Koko is sick.

He has a fever.

He also has a cough.

He is sleeping now.

The doctor is already in the house.

She examines Koko.

She gives Koko injection and some medicine.

Koko can not go to school.

He can not play with his friends.

\section{ANSWER THESE COMPREHENSION QUESTIONS}

1. Where is the car?

2. Is the car beside Koko's house?

3. Is it father's car?

4. Is it the doctor's car?

5. Is Koko healthy?

6. Is Koko sick?

7. Does Koko have a fever?

8. How is Koko?

9. What is Koko doing?

10.1 s the doctor in the car?

11.Is the doctor a man?

12. Who examines Koko?

13. What does the doctor give to Koko? 
Pembelajaran Bahasa Inggris ...

\section{Can Koko go to school? \\ 15. Why can"t Koko play with his friends?}

Seminggu berikutnya, kepada warga belajar yang sama diberi materi pelajaran yang serupa yaitu bacaan yang berisikan kalimat-kalimat sederhana tentang "simple present tense" bedanya kali ini materi pelajaran ini diberikan dengan menggunakan media batang es krim sebagai media pembelajaran.

\section{READING}

Today is Sunday.

Ayu doesn"t go to school.

She wants to go to "Hero" supermarket.

It is near her house.

Does she go there alone?

No, she doesn"t

She goes there with her brother, Anton.

They go shopping there every Sunday

What do they buy in the supermarket?

Ayu buys chocolate and candies

Anton buys new slippers

Do they buy drinks?

Yes, they do.

At two o"clock, they go home.

\section{ANSWER THESE COMPREHENSION QUESTIONS!}

1. What is the day today?

2. Is today Sunday?

3. Is today Monday?

4. Is the supermarket near her house?

5. Does Ayu go to school on Sunday?

6. Does Ayu go to school on Monday?

7. Where does Ayu want to go?

8. Does Ayu want to go to school?

9. Does Ayu want to go to "Hero" supermarket?

10.Does she go there alone?

11.Does she go there with her mother?

12.Does she go there with her brother?

13.Who is Anton?

14.When do they go shopping?

15.Do they go shopping every month?

16. What do they buy in the supermarket?

17.Do Ayu and Anton buy present for her mother?

18.Does Anton buy chocolate and candies?

19. Do they buy drinks?

20.At what time do they go home?

Materi terakhir di atas inilah yang diberikan/ diterapkan kepada warga belajar dengan menggu- nakan ice-cream sticks atau batang es krim sebagai media pembelajaran. Berikut adalah cara-cara penerapan media batang es krim ini.

Step 1: Membuka kelas

Salah satu hal yang sebaiknya dilakukan oleh tutor pertama-tama adalah membuka kelas. Pardiyono (2010: 1) menyatakan: Ibarat menyuguhkan makanan pembangkit selera (appetizer) dalam proses pembelajaran para guru harus membuka kelas paling tidak dengan dua hal penting, yaitu greeting dan checking the attendance.

Greeting yang biasa dilakukan di kelas ini adalah

Teacher : Good morning students!

Students : Good morning, miss

Teacher : How are you students?

Students : Fine, Miss. How are you, Miss?

Teacher : Fine, too. Are you ready to study

English?

Students : Yes, Miss!.

Kemudian dilanjutkan dengan checking the attendance atau mengabsen warga belajar satu persatu Step 2 : Warga belajar dibagi menjadi dua kelompok. Oleh karena terdapat 17 orang warga belajar maka kelompok satu beranggotakan 8 orang dan kelompok dua beranggotakan 9 orang

Step 3 : Terlebih dahulu tutor menyiapkan papan tulis. Tutor membuat format seperti berikut ini.

\begin{tabular}{|c|c|l|}
\hline NO & ENGLISH & INDONESIAN \\
\hline 1. & T & \\
\hline 2. & A & \\
\hline 3. & S & \\
\hline 4. & I & \\
\hline 5. & D & \\
\hline 6. & N & \\
\hline 7. & S & \\
\hline 8. & T & \\
\hline 9. & W & \\
\hline 10. & A & \\
\hline 11. & A & \\
\hline 12. & D & \\
\hline 13. & Y & \\
\hline 14. & A & \\
\hline
\end{tabular}

Papan tulis ini nanti akan digunakan untuk menuliskan kalimat yang terdapat pada batang es yang diperoleh. Hal ini dilakukan untuk mengantisipasi kelemahan media ini. Karena batang-batang es krim dan tulisannya terlalu kecil sehingga tidak dapat dilihat dan dibaca bersama. Inisial huruf awal pada setiap kalimat Bahasa Inggris diharapkan dapat membantu warga belajar dalam menganalisis kalimat mana yang dimaksud. Penulis sengaja memasukkan unsur trans- 
lation ke dalam pembelajaran ini untuk mempermudah warga belajar dalam menyusun kalimat-kalimat tersebut menjadi sebuah bacaan.

Step 4 : Di atas meja, tutor menggenggam semua batang es krim (28 buah), lalu melepaskannya.
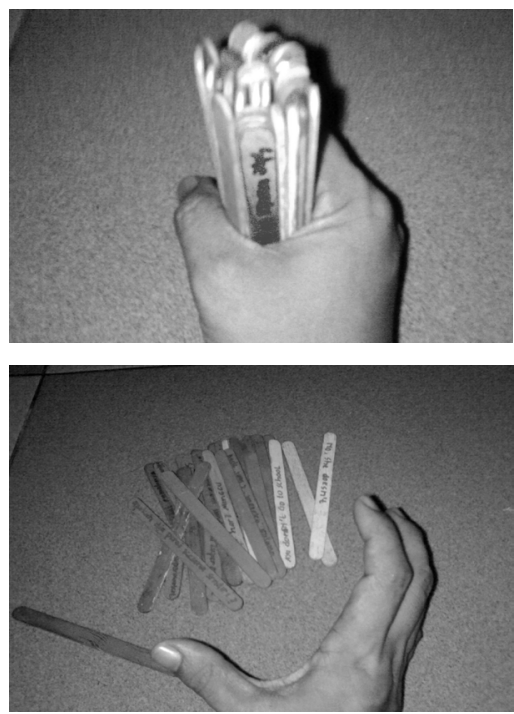

Gambar Step 4

Step 5: Permainan dimulai.

Tutor meminta salah satu wakil dari kelompok satu untuk mulai mengambil 'sticks' yang terserak/ tertumpuk di atas meja dengan menggunakan tangan atau sticks yang didapat tanpa menggerakkan sedikitpun stick yang lain. Jika stick yang lain ikut bergerak maka kelompok satu out/quit.

Di sini tutor berperan sangat penting, keputusan bergerak tidaknya stick yang lain ada di tangan tutor. Agar permainan dapat berlangsung tertib, tutor harus tegas dalam menilai permainan masing-masing kelompok. Di sini, tutor dapat melihat warga belajar mana yang aktif dan yang tidak.
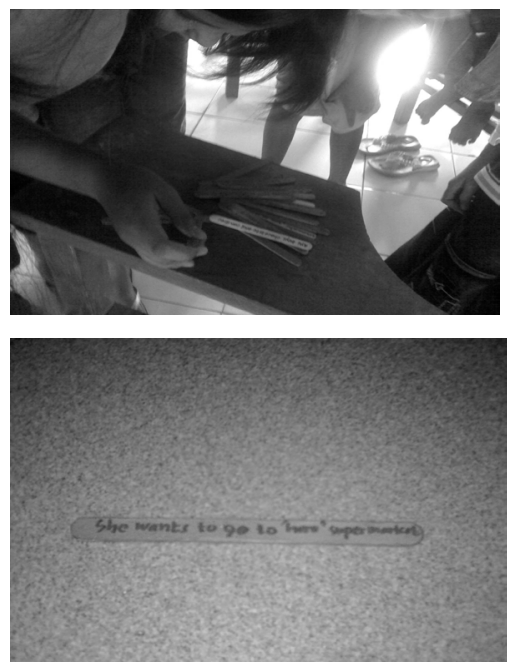

Gambar Step 5
Step 6: Dengan bimbingan tutor,batang es krim yang didapat kemudian diminta untuk dibaca dengan keras agar semua warga dapat mendengar.

Step 7: Setelah kelompok satu selesai, kini giliran kelompok dua yang bermain. Tutor kemudian menggenggam "sticks" yang tersisa dan melepaskannya. Kembali di atas meja.

Step 8: Kelompok kedua melakukan hal yang sama seperti yang dilakukan oleh kelompok satu yaitu, mengambil sticks yang terserak tanpa menggerakkan stick yang lain dan membacakannya dengan keras.

Step 9: Setelah semua sticks habis, maka dihitung berapa banyak batang es krim yang didapat oleh masing-masing kelompok. Kelompok yang paling sedikit mendapat batang es krim adalah kelompok yang kalah dan bisa diberi hukuman. Misal, menyanyi dalam Bahasa Inggris.

Step10: Masing masing kelompok mendiskusikan batang-batang es krim yang didapat. Perhatikan huruf awal pada masing-masing kalimat Bahasa Inggris yang didapat. Kemudian dicari mana kalimat-kalimat yang berpasangan (Inggris-Indonesia). Setelah mendapat persetujuan tutor, kemudian dituliskan di papan tulis. Di sini dilihat lagi, kelompok yang paling banyak mendapatkan kalimat yang berpasangan adalah pemenangnya.

Step 11: Kini yang tersisa tinggal batang-batang es krim yang tidak memiliki pasangan. Kemudian kelompok satu membacakan satu kalimat dan kelompok dua menunjukkan stick yang menjadi pasangannya. Semua sticks disusun di atas meja sama dengan susunan di papan tulis.

Step 12: Setelah semua kalimat sudah tersusun dengan benar, maka tutor bisa meminta salah satu warga belajar dari kelompok satu untuk membaca kalimat Bahasa Inggris dan warga belajar dari kelompok dua membaca kalimat Bahasa Indonesia.

Step 13: Jika dirasa warga belajar sudah cukup mengerti dengan isi bacaan tersebut barulah diberikan pertanyaan atau comprehension questions untuk dijawab. Namun tutor masih harus memberi kepada mereka karena memang mengajar warga belajar kesetaraan harus lebih sabar.

Dalam pembelajaran menggunakan media ice cream sticks ini penulis merasakan betul akan keaktifan dan antusias warga belajar dalam mengikuti pembelajaran Bahasa Inggris. Pardiyono (2010) menegaskan bahwa dalam proses pembelajaran Bahasa Inggris masa kini, para guru tidak hanya berperan sebagai sebagai spoon-feeder, akan tetapi lebih berperan sebagai sebagai fasilitator, konduktor dan motivator 
yang dapat membimbing para siswa menjadi lebih aktif, reaktif dan eksploratif. Konteks kelas yang demikian ini memerlukan seorang guru yang energik yang dapat menjadikan kelas hidup. Di sini jelas bahwa seorang tutor sangat berperan penting dalam proses pembelajaran untuk membimbing warga belajar memahami materi yang sedang disajikan di samping penggunaan metode yang sesuai untuk para peserta didik.

\section{METODOLOGI PENELITIAN}

Media pembelajaran ini diterapkan kepada warga belajar paket $B$ binaan UPTD Sanggar Kegiatan Belajar (SKB) pada bulan Mei 2010. Penerapan pertama dengan 13 orang warga belajar dan penerapan kedua dengan 17 orang warga belajar.

Pengolahan data yang didapat akan menggunakan "criterion reference method." Menurut Mayo $(1988 ; 18)$ metode ini sering digunakan karena memiiki keuntungan mudah dihitung dan dimengerti. Sedangkan Tinambunan $(1988 ; 129)$ menyatakan

And if the standard for mastery has been appropriately set. The letter grades in a criterion-reference system may be defined as the degree to which the objectives have been attained. The student's attainment of the course's objectives can be indicated by the use of five letters $A-B-C-D-E$ system which expresses various level of achievement.

Dari pernyataan di atas, jelas bahwa metode kriteria menggunakan sistem lima huruf untuk menilai pencapaian siswa. Perhatikan tabel berikut ini.

Tabel 2

Pedoman Metode Kriteria

\begin{tabular}{|c|c|c|}
\hline $\begin{array}{c}\text { Percentage Of } \\
\text { Correct Answer }\end{array}$ & Grades & $\begin{array}{c}\text { Levels Of } \\
\text { Achievement }\end{array}$ \\
\hline $93-100 \%$ CA & A - Outstanding & $\begin{array}{c}\text { Oustanding } \\
\text { Achievement }\end{array}$ \\
\hline $85-92 \%$ CA & B - Very Good & $\begin{array}{c}\text { Above Average } \\
\text { Achievement }\end{array}$ \\
\hline $75-84 \%$ CA & C - Satisfactory & $\begin{array}{c}\text { Average Achieve- } \\
\text { ment }\end{array}$ \\
\hline $60-74 \%$ CA & D - Very Weak & $\begin{array}{c}\text { Below Average } \\
\text { Achievement }\end{array}$ \\
\hline $\begin{array}{c}\text { Below } 60 \% \\
\text { CA }\end{array}$ & E - Fail & $\begin{array}{c}\text { Insufficient } \\
\text { Achievement }\end{array}$ \\
\hline
\end{tabular}

Prosedur dari metode kriteria ini adalah sebagai berikut.

1. Susun data menurut ranking dari nilai C.A (Correct Answer) atau jawaban benar yang tertinggi.

2. Cari persentase nilai siswa/warga belajar dengan menggunakan rumus sebagai berikut;

$\mathrm{CA} / \mathrm{N} \times 100 \%$

Dimana, $\mathrm{CA}=$ Jawaban Benar

$\mathrm{N}=$ Jumlah soal

3. Buat tabel nilai dan pencapaian siswa, seperti berikut.

Tabel 3

Tabel Nilai dan Pencapaian Siswa

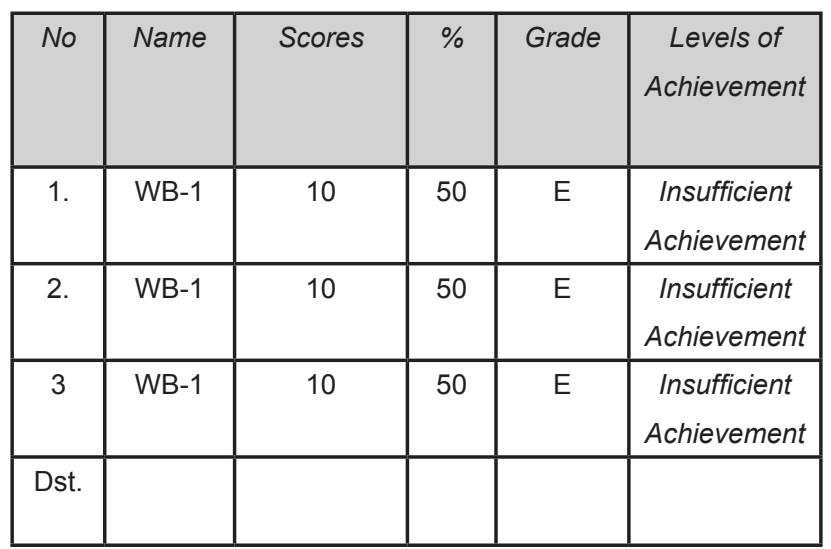

Berdasarkan tabel di atas, maka untuk menghitung persentase warga belajar yang mendapat nilai $\mathrm{A} / \mathrm{B} / \mathrm{C} / \mathrm{D} / \mathrm{E}$ dengan menggunakan rumus berikut.

Siswa yang mendapat nilai A/B/C/D/E X 100\%Jumlah siswa yang ikut tes

\section{HASIL DAN PEMBAHASAN}

Hasil yang didapatkan dari dua kali pembelajaran adalah sebagai berikut.

\section{Pembelajaran Pertama}

Tabel berikut ini adalah hasil pembelajaran pertama yang dilakukan tanpa menggunakan media ice cream sticks (batang es krim)
Tabel 4

Hasil Pembelajaran Pertama

\begin{tabular}{|c|c|c|c|c|c|}
\hline No & Name & Score & $\%$ & Grade & $\begin{array}{c}\text { Levels Of } \\
\text { Achievement }\end{array}$ \\
\hline 1. & WB - 1 & 14 & 93 & A & Outstanding \\
\hline 2. & WB -2 & 10 & 66,7 & D & Below average \\
\hline
\end{tabular}




\begin{tabular}{|c|c|c|c|c|c|}
\hline No & Name & Score & $\%$ & Grade & $\begin{array}{c}\text { Levels Of } \\
\text { Achievement }\end{array}$ \\
\hline 3. & WB - 3 & 10 & 66,7 & $\mathrm{D}$ & Below average \\
\hline 4. & WB - 4 & 9 & 60 & $\mathrm{D}$ & Below average \\
\hline 5. & $\mathrm{WB}-5$ & 9 & 60 & $\mathrm{D}$ & Below average \\
\hline 6. & $\mathrm{WB}-6$ & 8 & 53,3 & $\mathrm{E}$ & Insufficient \\
\hline 7. & $\mathrm{WB}-7$ & 8 & 53,3 & $\mathrm{E}$ & Insufficient \\
\hline 8. & $\mathrm{WB}-8$ & 7 & 46,7 & $\mathrm{E}$ & Insufficient \\
\hline 9. & $\mathrm{WB}-9$ & 2 & 13,3 & $\mathrm{E}$ & Insufficient \\
\hline 10. & $\mathrm{WB}-10$ & 1 & 6,7 & $\mathrm{E}$ & Insufficient \\
\hline 11. & $\mathrm{WB}-11$ & 0 & 0 & $\mathrm{E}$ & Insufficient \\
\hline 12. & $\mathrm{WB}-12$ & 0 & 0 & $\mathrm{E}$ & Insufficient \\
\hline 13. & $\mathrm{WB}-13$ & 0 & 0 & $\mathrm{E}$ & Insufficient \\
\hline
\end{tabular}

Berdasarkan tabel di atas, maka kita akan mendapatkan tabel pencapaian warga belajar sebagai berikut.

Tabel 5

Hasil Pencapaian Pembelajaran Pertama

\begin{tabular}{|c|c|c|c|}
\hline No. & Levels Of Achievement & $\begin{array}{c}\text { Number Of } \\
\text { Students }\end{array}$ & $\%$ \\
\hline 1. & Outstanding (A) & 1 & 7,7 \\
\hline 2. & Above Average (B) & -- & -- \\
\hline 3 & Average (C) & -- & -- \\
\hline 4. & Below Average (D) & 4 & 30,8 \\
\hline 5. & Insufficient (E) & 8 & 61,5 \\
\hline
\end{tabular}

Di sini jelas terlihat bahwa hanya satu orang warga belajar dari 13 orang warga belajar yang ikut dalam pembelajaran pertama, yang dapat mencapai outstanding achievement level (A) . Tidak ada seorang warga belajarpun yang dapat mencapai above average level (B) dan average level (C). Kebanyakan warga belajar berada pada level terendah, yaitu insufficient level ( 8 warga belajar). Selain itu tampak pula pada tabel bahwa $30,8 \%$ atau 4 orang warga belajar berada pada below average level. Jadi di sini dapat disimpulkan bahwa pencapaian warga belajar terhadap pelajaran reading ini sangat kurang sekali. Hal ini dipengaruhi oleh banyak faktor, antara lain kurangnya minat warga belajar terhadap pembelajaran ini karena dianggap tidak menarik dan cara pembelajaran yang monoton serta media pembelajaran yang kurang tepat.

\section{Pembelajaran Kedua}

Setelah penerapan media pembelajaran batang es krim, diperoleh hasil seperti tabel berikut.

Tabel 6

Hasil Pembelajaran Kedua

\begin{tabular}{|c|c|c|c|r|c|}
\hline No & Name & Score & $\%$ & Grade & $\begin{array}{c}\text { Levels Of } \\
\text { Achievement }\end{array}$ \\
\hline 1. & WB -1 & 20 & 100 & A & Outstanding \\
\hline 2. & WB -7 & 20 & 100 & A & Outstanding \\
\hline
\end{tabular}

\begin{tabular}{|c|c|c|c|c|c|}
\hline No & Name & Score & $\%$ & Grade & $\begin{array}{c}\text { Levels Of } \\
\text { Achievement }\end{array}$ \\
\hline 3. & WB - 4 & 20 & 100 & A & Outstanding \\
\hline 4. & WB - 5 & 18 & 90 & B & Above Average \\
\hline 5. & WB - 2 & 18 & 90 & B & Above Average \\
\hline 6. & WB - 15 & 18 & 90 & B & Above Average \\
\hline 7. & WB - 6 & 18 & 90 & $B$ & Above Average \\
\hline 8. & WB - 3 & 18 & 90 & B & Above Average \\
\hline 9. & WB - 14 & 15 & 75 & $C$ & Average \\
\hline 10. & WB - 16 & 14 & 70 & D & Below Average \\
\hline 11. & WB - 17 & 14 & 70 & D & Below Average \\
\hline 12. & WB - 8 & 13 & 65 & D & Below Average \\
\hline 13. & WB - 11 & 12 & 60 & $D$ & Insufficient \\
\hline 14. & WB - 10 & 12 & 60 & $D$ & Insufficient \\
\hline 15. & WB - 9 & 10 & 50 & $E$ & Insufficient \\
\hline 16. & WB - 12 & 3 & 15 & $E$ & Insufficient \\
\hline 17. & WB - 13 & 2 & 10 & E & Insufficient \\
\hline
\end{tabular}

Dari tabel di atas maka didapat tabel pencapaian warga belajar berikut ini

Tabel 7

Hasil Pencapaian Pembelajaran Kedua

\begin{tabular}{|c|c|c|c|}
\hline No. & Levels Of Achievement & $\begin{array}{c}\text { Number Of } \\
\text { Students }\end{array}$ & $\%$ \\
\hline 1. & Outstanding (A) & 3 & 17,7 \\
\hline 2. & Above Average (B) & 5 & 29,4 \\
\hline 3. & Average (C) & 1 & 5,9 \\
\hline 4. & Below Average (D) & 5 & 29,4 \\
\hline 5. & Insufficient (E) & 3 & 17,7 \\
\hline
\end{tabular}

Dari dua tabel di atas, dapat dilihat bahwa pembelajaran dengan menggunakan batang es krim sebagai media pembelajaran memberikan dampak yang positif terhadap peningkatan pencapaian terhadap pembelajaran reading bagi warga belajar paket B setara SMP binaan SKB Kota Palembang. Di sini penulis tidak melihat kasus ini secara personal. Artinya penulis tidak melihat pencapaian ini orang perorang. Penulis hanya melihatnya secara keseluruhan. Setelah media batang es krim diterapkan maka tampak peningkatan terhadap pencapaian warga belajar terhadap isi bacaan yang diberikan. Dari dua puluh soal yang diberikan kepada 17 orang warga belajar terdapat tiga warga belajar yang dapat mencapai outstanding level (A). Lima orang warga belajar berada pada posisi above average level of achievement (B) . Pada pembelajaran pertama terdapat $61,5 \%$ atau delapan dari tiga belas warga belajar yang berada pada posisi pencapaian level terbawah yaitu insufficient level (E), sedangkan setelah menggunakan media batang es krim hanya terdapat $17,7 \%$ atau tiga orang dari tujuh belas orang warga belajar yang mengikuti pelajaran itu. 
Jadi dapat disimpulkan di sini bahwa terdapat kenaikan pencapaian pemahaman terhadap reading yang dipelajari dengan menggunakan media batang es krim.

Penerapan media batang es krim terhadap warga belajar memberikan beberapa hal positif sehingga dapat mempengaruhi motivasi warga belajar dalam mengikuti pembelajaran Bahasa Inggris, antara lain:
1. Proses belajar mengajar menjadi lebih menyenangkan sehingga warga belajar tidak merasa terbebani dengan pelajaran yang seringkali dianggap sebagai "momok" bagi mereka.

2. Karena suasana yang tidak menegangkan, warga belajar tidak merasa malu/takut pada saat disuruh membaca kalimat - kalimat Bahasa Inggris.

\section{PENUTUP}

Media ice cream sticks memang diterapkan dalam mata pelajaran Bahasa Inggris namun tidak menutup kemungkinan untuk dikembangkan dan dapat digunakan pada mata pelajaran yang lain. Penulis merasakan betul antusiasme warga belajar dalam proses belajar mengajar dengan menggunakan media batang es krim ini.

Dari penerapan media batang es krim yang dilaksanakan pada pertengahan bulan Mei 2010 ini, dapat ditarik kesimpulan bahwa penggunaan media ice cream sticks atau media batang es krim pada pembelajaran Bahasa Inggris memberikan dampak yang sangat positif bagi pencapaian tingkat pemahaman (comprehension) terhadap materi bacaan yang diberikan. Hal ini terbukti dengan meningkatnya levels of achievement warga belajar setelah media batang es krim ini diterapkan.

Selain itu pada proses belajar mengajar yang dapat langsung penulis observasi dan rasakan bahwa warga belajar menjadi begitu bersemangat dan bisa sedikit bersaing dan kreatif untuk mendiskusikan letakletak kalimat.

Ada beberapa kelebihan yang bisa diperoleh dari media batang es krim ini, yaitu;

1. Proses Belajar Mengajar (KBM) menjadi lebih menarik dan menyenangkan (interesting and fun) sehingga warga belajar menjadi lebih termotivasi untuk mempelajari pelajaran yang seringkali membosankan mereka.

2. Pembuatan media batang es krim ini tidak memer- lukan biaya yang mahal

3. Mudah untuk dimodifikasi untuk dapat digunakan mengajarkan skills yang lain, misalnya: conversation, grammar atau vocabulary.

Adapun kelemahan dari media batang es krim ini , yang sampai saat ini diketahui penulis, adalah ;

1. Karena batang es krim ini bentuknya tidak terlalu besar sehingga tidak dapat diletakkan dipapan tulis. Untuk itu penulis menggunakan papan tulis sebagai media penulisan kalimat-kalimat tersebut agar dapat dilihat, dibaca dan dipelajari bersama.

2. Karena metode ini berbentuk permainan maka suasana kelas menjadi sedikit ribut maka untuk itu tutor harus dapat sedikit membatasi pola tingkah para warga belajar agar mereka tetap terkontrol

Karena sudah terbukti memberikan dampak yang positif dalam pembelajaran Bahasa Inggris, untuk itu penulis merekomendasikan media batang es krim ini kepada :

1. Pamong belajar/tutor,

Agar dapat lebih kreatif untuk dapat mengembangkan media batang es krim ini dapat dipakai untuk materi-materi lain dan tidak menutup kemungkinan untuk menjadi media yang dapat dipergunakan pada mata pelajaran lain.

2. Kepala Sanggar Kegiatan Belajar (SKB) agar media ini dapat disebarluaskan kepada pamong belajar/ tutor Bahasa Inggris pada Paket B dan Paket C untuk diterapkan dalam proses belajar mengajar (tatap muka).

\section{DAFTAR PUSTAKA}

Djoko Smd \& Cahyono, S. (2007). Kamus populer bergambar (Inggris - Indonesia). Surabaya: Amelia

Mayo S.T. (1980). Interpreting test performance. New Directness For testing and measurement. San Fransisco: Jossey - Bas. Inc

Pardiyono. (2010). Pasti bisa; The art of teaching, technique of class handling as food - Like service.
Yogyakarta: Andi

Tinambunam, W. (1988). Evaluation of student achievement. Jakarta: Departemen Pendidikan dan Kebudayaan

UU RI No. 20 tahun 2003. (2008). Sistem pendidikan nasional. Jakarta: Sinar Grafika 